\title{
MUSIC COMPUTER EDUCATION CONCEPT FOR TEACHERS: RAISING THE PROBLEM
}

\author{
Irina B. Gorbunova Andreas Kameris
}

\begin{abstract}
The beginning of the 21th century was marked by the introduction of computer and communication technologies in all spheres of human activity. Global changes have occurred in the way information is transmitted and presented. Digital technology has penetrated into music and education. The achievements of sound recording, the technology of creating musical compositions combined with the new mass media possibilities have defined the previously non-existent areas of development and distribution of music, and require such knowledge that musicians who have received a classic music education do not have.The article describes the basic, which is devoted to development of actual theoretical and practical basis of raising knowledge of students in music department with usage of music computer technologies.
\end{abstract}

Keywords: music education, musical computer, music computer technologies

\section{Introduction}

The development of a new approach to higher, vocational musical education has resulted from the need to solve the most acute problems in mass music pedagogy, including the current state of general music education. Conservatory named after N. A. RimskyKorsakov from 2002 to 2017, musicologists, teachers of musical disciplines, researchers, teachers-practices noted that despite outstanding creative achievements, the possibilities of music education in mass pedagogy are not being fully exploited and the teaching methods in the system of general music education do not change significantly.

So, for example, at the annual International research and practical conference Contemporary Musical Education, held together by the Herzen State Pedagogical University of Russia and Saint Petersburg State.

Revised Manuscript Received on July 05, 2019.

Irina B. Gorbunova

Herzen State Pedagogical University of Russia, St. Petersburg, Russia

Andreas Kameris
Herzen State Pedagogical University of Russia, St. Petersburg, Russia

One of the ways to solve this problem would be to find new educational technologies. They need to be improved by creating musical programs that would allow flexible and diversified use of the variety of rich pedagogical tools in teaching music and the huge possibilities of a music computer, contemporary music computer technologies (MCT).

\subsection{Information technology in music education}

The process of informatization of education is one of the most important in the system of professional development of teachers (including musicians). Today, the network technology and Internet are increasingly being used to solve this task. More opportunities associated with the use of modern information technology are being created. A professional pedagogical network of teachers has been formed, that allows them to communicate with each other without leaving the educational institution.

However, there are a number of problems in this new field. Many educational institutions do not always have time to follow the rapidly changing world of digital technology. There is a need to create mobile educational systems which can quickly adjust to the changing information and communication environment. The problem of training specialists who meet the modern requirements of music education arose.

Thus, music computer technologies (MCT), dynamically developing, have determined the possibility of creating a new vocational educational and creative environment.

The didactic aspects of the problem of computerization of music education in Russia were developed by researchers, composers and teachers: Gennady G. Belov, Bulat M. Galeev, Irina B. Gorbunova, Mikhail $\mathrm{S}$. 
Zalivadny, Andreas Kameris, Maxim I. Karpets, Igor M. Krasilnikov, Elena V. Orlova, Rudolf Kh. Zaripov, Pavel L. Zhivaykin, Sergey P. Polozov, Marina.V. Karaseva, Yu.N. Rags, Mikhail G. Svetlov, Imina G. Alieva (Russia - Azerbaijan), Natalia S. Sushkevich (Russia - Belarus) and others. Scientific articles and monographs [9], teaching and learning aids [3], programs and sheet music for students are published in this regard. The Music and Electronics magazine, which is in publication since 2003, has been providing the assistance to the teacher with the selection of equipment, repertoire for music classes, the methodology for conducting them, etc. Since 2013, the materials of scientific research of scientists involved in the study of the possibility of inclusion of MCT in the system of contemporary musical education in the journal Music Scholarship are published [4].

Nevertheless, despite the demand for information technologies in music [2] in music practice and the development of a number of theoretical aspects of the considered problem [1], the topic of competent, adequate and scientifically grounded point of view of their use in the system of contemporary musical education remains open. Not enough attention is paid to the introduction of the MCT to the education system; therefore, a serious scientific generalization of what has been done in this area is required, taking into account the results of the rapid development of $\mathrm{MCT}$, digital arts, electronic musical instruments (EMI) [5], [6].

In this regard, the experience of creating and implementing of the music computer pedagogical education concept in the educational and methodical laboratory Music Computer Technologies at the Herzen State Pedagogical University of Russia is extremely valuable. The music computer education concept consists of the development of higher musical pedagogical education on the basis of MCT (Bachelor and Master programs "Music Computer Technologies" and "Music Computer Technologies in Education"), as well as the implementation of professional retraining programs, including "Teaching Music Disciplines with Using Music Computer Ttechnologies" and "Teaching Electronic Musical Synthesizer".

\subsection{Musical computer}

In the process of establishing a musical computer there are two main prerequisites for its development. The first is the musicians' aspiration to enrich their music art. The second one is related to the historical improvement of musical tools, based on the modern achievements of science and technology in the field of sound production design-wise. It is important to note the evolution of musical synthesizers, including automated musical instruments from the moment of their genesis to the present days [7], [8], [9].

Musical instruments or synthesizers, widely used as generators of sounds, are controlled by various methods (mechanical, electrical, optical, etc. effects), as well as various methods of concentration and amplification of sound [10]. The development of electronic musical instruments (EMI) has boosted the creation of electronic musical synthesizers, where on one hand, previously used methods of sound synthesis have found their further development, and on the other hand, fundamentally new methods have been introduced [11], [12], [13], [14]. An electronic musical synthesizer is an instrument that electronically generates and modifies sound, using a computer (digital music synthesizer) or without it (analog music synthesizer). Electronic synthesizers are used to create music (electronic music) and perform lives.

A musician playing the synthesizer, in addition to the possibility of traditional music-making, considers his instrument as a set of elements that he configures to create the desired timbre and the performance manner. This process is often referred to as "programming" or "patching", and it can occur both before and during music performance. In general, the modern keyboard synthesizer can be described as an digital keyboard interactive musical instrument intended for using as an autonomous instrument or a sound source in the system of electroacoustic musical hardware.

Over the course of our research work, the functional stages of a musical computer establishment, the evolution of electronic musical composition in interaction with a computer, a musical computer as a new multi-functional polytembral instrument of a musician were addressed.

The term "musical computer" means a class of electronic instruments optimized for solving specific tasks in the field of musical activity - a professional instrument in the field of music and education.

Summarizing the main musicians activities, where the computer music

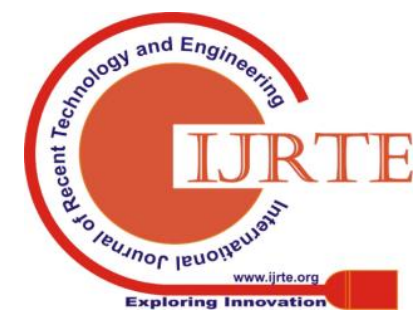


equipped with several sound sources (synthesizers, samplers, MIDI-keyboards or MIDI-controllers) plays an increasing role, we emphasize the highlights. First of all, these are sheet music publishing, phonograms production, arrangements and original compositions using sequencer programs, sound engineering, electronic sound synthesis, old records restoration, electronic music, interactive performance systems of algorithmic music, real-time score management systems, creation and use of musicological databases; as well as teaching music with the help of a music computer in secondary schools, learning the arrangement and composition via the music computer as a part of the system of musicians professional training, the development of creative and performing skills, music computer use in live performances, and many more.

Music computer technologies in the system of contemporary education for music teachers

The experience of understanding the historical, artistic, aesthetic, ideological and methodological foundations of the formation of music computer technologies, the processes of evolution, the penetration of the MCT into various forms and types of musical, creative and pedagogical activities should be designed as an obligatory component of musical and computer pedagogical education.

A new contemporary educational creative environment is being shaped of the main following components:

musical computer as a key element of hardware tools and the software for the music computer educational complex;

methodological tools and its methodological basis, allowing to use the MCT at all stages and in all areas of the musical and educational processes (we emphasize that the MCT require the constant development of new training programs and courses adjusted to modern social needs and corresponding to the development level of these technologies);

- socio-cultural factor of comprehensive human development education.

The most important music computer technologies application and development areas today are:

- MCT in professional music education (as a mean to expand creative opportunities);
MCT in general education (as one of the means of education);

MCT as a means of rehabilitation of disabled people;

MCT as a new direction of music-technological experts of education, associated, in particular, with the modelling of elements of music.

In our study only the first issue is being addressed. However, as the main defining component of the unified musical and educational process, it also includes other areas of the MCT use.

\section{Conclusion}

It should be noted that the use of modern MCT in the system of contemporary musical education (general, professional, additional professional, postgraduate) is still challenging. This process is characterized by many contradictions, the main of which are:

- the gap between conceptual innovations in the fields of general pedagogy, focused on the widespread use of new information educational technologies, and academic musical pedagogy;

- the gap between the capabilities of the MCT and the real demand for them in the music education system (general as well as vocational);

- the traditional focus on the specific purpose of the music teacher and the integration of different fields of knowledge;

- incompatible programs, study plans for schools of general education and music schools, universities and the developments of creative laboratories, etc.

This list may be prolonged.

The lack of scientifically based methodological and psychological analysis of the existing MCT use experience and the prospects of their development in general and vocational music education requires working out the appropriate methods and forms of training. Therefore, the search for effective educational systems taking into account the capabilities of the MCT is promising and reasonable.

\section{References}

[1] Gorbunova, I.B. (2017). Information Technology

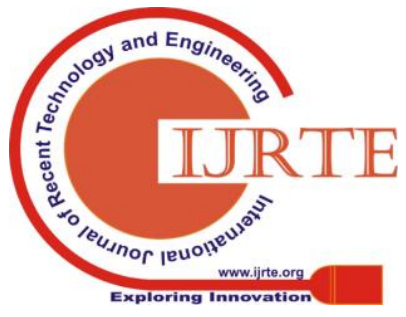


in Music and Music Education. The World of Science, Culture, Education, 2 (63), 206-210.

[2] Gorbunova, I.B. (2015). Computer Science and Computer Music Technologies in Education. Theory and Practice of Social Development, 12, $428-432$.

[3] Gorbunova, I.B. (2017). Music Computer: Modeling the Process of Musical Creativity. The World of Science, Culture, Education, 4 (65), 145148.

[4] Gorbunova, I.B. (2014). Music Computer Technologies in the Training of the TeacherMusician. Music Scholarship, 3 (16), 5-10.

[5] Gorbunova, I.B. (2018). New Tool for a Musician. In Prof. Dr. B. Topcuoglu, Prof. Dr. M. Plaisent, Dr. Thaweesak Yingthawornsuk (Ed), 15th Int'l Conference on Education, Economics, Humanities and Interdisciplinary Studies. EEHIS-18 International Conference Proceedings. 2018 (pp. 107-113). Paris, France. https://doi.org/10.17758/URUAE2.AE06184024

[6] Gorbunova, I.B. (2018). Electronic Musical Instruments: to the Problem of Formation of Performance Mastery. In Prof. Dr. Rahim Ahmadi, Prof. Kazuaki Maeda, Prof. Dr. M. Plaisent (Ed.), 16th International Conference on Literature, Languages, Humanities \& Social Sciences (LLHSS-18). Int'l Conference Proceedings (pp. 2329). Budapest, Hungary. https://doi.org/10.17758/ URUAE4.UH10184023

[7] Gorbunova, I.B. \& Govorova, A.A. (2018). Music Computer Technologies as a Means of Teaching the Musical Art for Visually-Impaired People. In Prof. Dr. Rahim Ahmadi, Prof. Kazuaki Maeda, Prof. Dr. M. Plaisent (Ed.), 16th International Conference on Literature, Languages, Humanities \& Social Sciences (LLHSS-18). Int'l Conference Proceedings (pp. 19 - 22). Budapest, Hungary. https://doi.org/10.17758/ URUAE4.UH10184022

[8] Gorbunova, I., \& Govorova. A. (2018) Music Computer Technologies in Informatics and Music Studies at Schools for Children with Deep Visual Impairments: From the Experience. In: Pozdniakov S., Dagienè V. (eds) Informatics in Schools. Fundamentals of Computer Science and Software
Engineering. ISSEP 2018. Lecture Notes in Computer Science, vol 11169. Springer, Cham DOI: https://doi.org/10.1007/978-3-030-027506_29

[9] Gorbunova, I. B., Kameris, A. The Concept of Music Computer Education in Preparing the Teacher-Musician: monograph. St. Petersburg: Publishing House of the Herzen State Pedagogical University of Russia, 2011.

[10] Gorbunova, I. B. \& Tovpich, I. O. (2015). Information educational environment as a resource of formation of information culture of participants of educational process in the school of the digital age, Theory and Practice of Social Development, 7, 192-196.

[11] Gorbunova I.B., Zalivadny M.S., \& Tovpich I.O. (2018). Mathematical Methods of Research in Musicology: An Attempt of Analyzing a Material from Contemporary Historical Heritage (Reflections on Xenakis' book Musiques formelles). In Prof. Dr. B. Topcuoglu, Prof. Dr. M. Plaisent, Dr. Thaweesak Yingthawornsuk (Ed), 15th Int'l Conference on Education, Economics, Humanities and Interdisciplinary Studies. EEHIS-18 International Conference Proceedings. 2018 (pp. 107-113). Paris, France. https://doi.org/10.17758/URUAE2.AE06184022

[12] Gorbunova, I. B., Zalivadny, M. S., \& Tovpich, I. O. (2016). On Leonhard Euler's Theory of Music. Parlando, $6 . \quad$ Retrieved from: http://www.parlando.hu/2016/2016-6/GorbunovaEuler.pdf

[13] Gorbunova, I. B., Zalivadny, M. S. (2018). The Integrative Model for the Semantic Space of Music: Perspectives of Unifying Musicology and Musical Education. Music Scholarship, 3, 55-64. DOI: http://dx.doi.org/10.17674/1997-0854.2018.4.055064

[14] Gorbunova, I. B., Zalivadny, M. S., \& Tovpich, I. O. (2014). Complex Model for Semantic Space of Music and the Prospects of the Interaction of Musical Science and the Modern Musical Education. Scientific Opinion, 8, 238-249.

Published By:

Blue Eyes Intelligence Engineering \& Sciences Publication

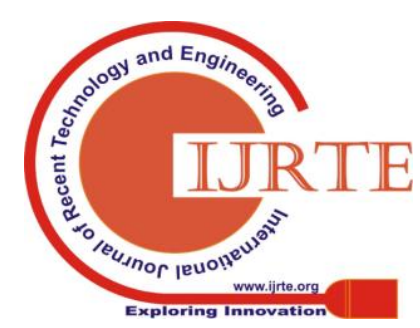




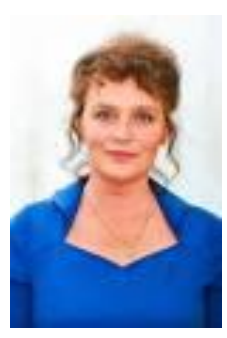

Irina B. Gorbunova was born in Saint Petersburg (Leningrad). DipMus, Special Music Higher School of the St. Petersburg State Conservatory named after N.A. Rimsky-Korsakov; BSc in Computer Science: Information Technology, Computer Science and Multimedia, Leningrad State University, Ussurisk State Pedagogical University; MA in Education, the Herzen State Pedagogical University of Russia; $\mathrm{PhD}$ in Information Technology and Pedagogical Sciences, the Herzen State Pedagogical University of Russia, St. Petersburg, 1989; Doctor degree: Doctor of Pedagogical Sciences and Information Technology, the Herzen State Pedagogical University of Russia, St. Petersburg, 1999. Dr. Gorbunova, Full Professor, PhD in Sc., Doctor of Pedagogical Sciences, Chief Researcher of the Educational and Methodological Laboratory Music Computer Technologies at the Herzen State Pedagogical University of Russia, St. Petersburg; hold the degree of Honorary Worker of Higher Professional Education of the Russian Federation.

Work experience:

1990 - 2010 - Associate Professor, Professor of the Department of Information Technology of the Herzen State Pedagogical University of Russia, St. Petersburg;

2010 - present - Full University Professor, Department of Information Technology, Institute of Computer Science and Technological Education at the Herzen State Pedagogical University of Russia, St. Petersburg;

2002 - present - Chief Researcher of the Educational and Methodological Laboratory Music Computer Technologies of the Herzen State Pedagogical University of Russia, St. Petersburg.

She has more than 300 scientific publications, among them are monographs Music Computer Technologies: Historical-Theoretical and Practical Aspects, St. Petersburg: Publ. House "SMIO Press" (2007.) and Music Computer Technologies: The Problem of Modeling the Process of Musical Creativity, compiled with participation of $\mathrm{S}$. V. Chibirev, St. Petersburg: Publ. House of the Herzen
State Pedagogical University of Russia (2012); course book Information Technology in Music, vol. 1 - 4: vol. 1, Architectonics of Musical Sound (2009, 175 pp.), vol. 2, Musical Synthesizers, 2010; vol. 3, Musical Computer, 2011; Music, Mathematics and Computer Science, vol. 4, 2013, St. Petersburg: Publ. House of the Herzen State Pedagogical University of Russia.

Prof. Dr. Gorbunova is a Chairman of the annual Iinternational Research and Practical Conference Contemporary Music Education held since 2002; Chairman of the annual International Research and Practical Conference Music Computer Technologies in the System of Contemporary Education held since 2007.

Dr. Gorbunova is a member of the Jury of national and international competitions of musical creative works, including Electronic Palette (SaintPetersburg), Music and Electronics (Moscow), Music of the XXI Century (Moscow / SaintPetersburg), International Festivals and Competitions Musical Electronics and Multimedia (Moscow / Saint-Petersburg), CLARINE of the 21 $1^{\text {st }}$ Century (Saint-Petersburg), The World of Art without Borders (Saint-Petersburg, Russia - Szeged, Hungary), Bridge of Friendship (Dortmund, Germany), All-Russian Competition of Electroacoustic Music DEMO (Saint-Petersburg).

Prof. Dr. Gorbunova has developed first ever course in Music, called 'Music Computer Technologies', which has been offered under the Bachelors of Arts and Sciences (BASc), and she also leads postgraduate course "Music Computer Technologies in Education" available under the MA in Music Education.

Prof. Dr. Gorbunova supervises a number of doctoral and post-doctoral students (more than 30) and lectures on Music Computer Technologies and Information Technology in Music. She supervises research in various directions, among them there are: Theory and History of Culture, Music Art, Information System and Processes, Theory and Methodology of Professional Education, Mathematical Modelling, Numerical Methods and Program Ssystems, Theory and Methods of Education and

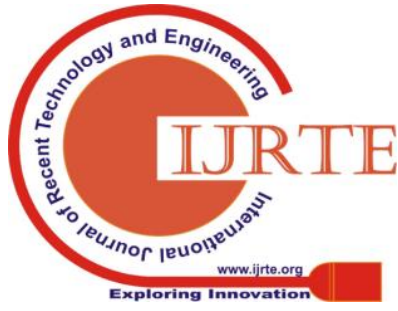


Upbringing (in Music, Informatics, natural sciences). The research results of Prof. Gorbunova were published in over 300 refereed publications including 49 books and 277 papers in various scientific journals.

Her research activities include such directions as: MCT in professional music education (as a means to expand creative opportunities); MCT in general musical education (as one of the means of education); MCT as a means of rehabilitation of people with disabilities; MCT as the new direction in preparation of specialists of humanitarian and technological profile; MCT in the field of digital arts; MCT in information technology, psychoacoustics and musical acoustics; system of training arrangements and the art of performing skills on electronic musical instruments. Her circle of interests also includes the problems of interrelation of natural and technical sciences and humanities, as well as the possibilities of applying the results of such interrelation for the purposes of music education and upbringing. She also takes part in working out the specialized software for computer music devices and in application of this software in pedagogical processes. Her developments and researches also belong to the field of musical pedagogics and musicology, musical informatics, computer modeling of processes of musical creativity, timbre programming, art of performing skills and arrangement on electronic musical instruments, creative work in the field of computer music, mathematical methods in musicology.

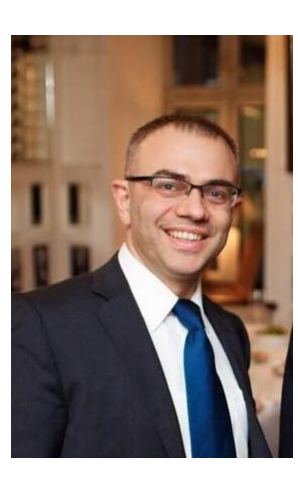

Andreas Kameris was born in Nicosia, Cyprus.

2001 - Master of Musical Arts (composition) - St. Petersburg State Conservatory; 2005 - Doctor of Musical Arts - St. Petersburg State Conservatory; 2007 - PhD Herzen State Pedagogical University of Russia, St. Petersburg.
2001 - 2003 - Lector at St. Petersburg Bershadsky Private Conservatory

2002 - present - Research Scientist and Lector at the Educational and Methodical Laboratory Music Computer Technologies, Herzen State Pedagogical University of Russia

2005 - 2012 - Visiting Lector at ARTE Music Academy, Nicosia, Cyprus.

Main publications: Gorbunova I., Kameris A. The Concept of Music Computer Education in Preparing the Teacher-Musician: monograph. St. Petersburg: Publishing House of the Herzen State Pedagogical University of Russia, 2011; Belychenko V., Gorbunova I., Kameris A. Music Computer Technologies in the Preparation of a Music Teacher. St. Petersburg: Herzen University Press, 2011; Belychenko V., Bryantsev M., Gorbunova I., Kameris A., Kibitkina E. Development of the Information Competency of a Modern musician based on Music Computer Technologies. St. Petersburg: Herzen University Press, 2012.

Andreas Kameris's compositions for symphony orchestra, small musical ensembles and chorus have been performed at various concerts and festivals. He has designed the Bachelor's degree program "Music Computer Technology" and the Master's degree program "Music Computer Technology in Education" accredited by the Ministry of Education of the Russian Federation. Since 2002, Andreas Kameris has been participating in the annual International Research and Practical Conference Contemporary Musical Education organized by the Herzen State Pedagogical University of Russia and the St. Petersburg State Conservatory. His articles have been published in various scientific journals and editions. He is a member of the jury of the composers competition Musical Palette held each year in St. Petersburg.

Published By:

Blue Eyes Intelligence Engineering \& Sciences Publication 